\title{
Characterization of in vitro haploid and doubled haploid Chrysanthemum morifolium plants via unfertilized ovule culture for phenotypical traits and DNA methylation pattern
}

\author{
Haibin Wang ${ }^{1,2}$, Bin Dong ${ }^{1}$, Jiafu Jiang ${ }^{1}$, Weimin Fang ${ }^{1}$, Zhiyong Guan ${ }^{1}$, Yuan Liao ${ }^{1}$, Sumei Chen ${ }^{1 *}$ \\ and Fadi Chen ${ }^{1,2 *}$
}

${ }^{1}$ College of Horticulture, Nanjing Agricultural University, Nanjing, China

2 Jiangsu Province Engineering Lab for Modern Facility Agriculture Technology \& Equipment, Nanjing, China

\section{Edited by:}

Thomas Debener, Leibniz University Hannover, Germany

Reviewed by:

Abdullahil Baque, Shere-Bangla Agricultural University, Bangladesh Frans Andries Krens, Wageningen University and Research Centre

Plant Science Group, Netherlands

${ }^{*}$ Correspondence:

Sumei Chen and Fadi Chen, Jiangsu Province Engineering Lab for

Modern Facility Agriculture

Technology \& Equipment, Nanjing

Agricultural University, Weigang No.

1, Nanjing 210095, China

e-mail: chensm@njau.edu.cn;

chenfd@njau.edu.cn
Chrysanthemum is one of important ornamental species in the world. Its highly heterozygous state complicates molecular analysis, so it is of interest to derive haploid forms. A total of 2579 non-fertilized chrysanthemum ovules pollinated by Argyranthemum frutescens were cultured in vitro to isolate haploid progeny. One single regenerant emerged from each of three of the 105 calli produced. Chromosome counts and microsatellite fingerprinting showed that only one of the regenerants was a true haploid. Nine doubled haploid derivatives were subsequently generated by colchicine treatment of 80 in vitro cultured haploid nodal segments. Morphological screening showed that the haploid plant was shorter than the doubled haploids, and developed smaller leaves, flowers, and stomata. An in vitro pollen germination test showed that few of the haploid's pollen were able to germinate and those which did so were abnormal. Both the haploid and the doubled haploids produced yellow flowers, whereas those of the maternal parental cultivar were mauve. Methylation-sensitive amplification polymorphism (MSAP) profiling was further used to detect alterations in cytosine methylation caused by the haploidization and/or the chromosome doubling processes. While $52.2 \%$ of the resulting amplified fragments were cytosine methylated in the maternal parent's genome, the corresponding proportions for the haploid's and doubled haploids' genomes were, respectively, 47.0 and $51.7 \%$, demonstrating a reduction in global cytosine methylation caused by haploidization and a partial recovery following chromosome doubling.

Keywords: chrysanthemum, haploid, double haploid, ovule culture, MSAP

\section{INTRODUCTION}

Chrysanthemum (Chrysanthemum morifolium) is a leading ornamental species and enjoys a wide acceptance in the world (Hall and Dickson, 2011; Teixeira da Silva et al., 2013). Intensive breeding has produced a large array of flower color and form, Nevertheless, market pressure for further innovation has driven the industry to continue to seek novelty, along with a continuous need to improve levels of biotic and abiotic stress resistance (Chandler and Sanchez, 2012). The allohexaploid status of the chrysanthemum's genome complicates breeding advance, which has become a major bottleneck for $C$. morifolium breeding, especially in the context of applying molecular breeding technologies (Kearsey, 2002; Thomas et al., 2003; Teixeira da Silva et al., 2013).

During the last decade, the current DNA sequencing platforms have had a major impact on plant genetics and breeding technology (Loman et al., 2012). However, species such as C. morifolium, which possess large and highly heterozygous genomes, remain difficult to handle at the sequence level (Shendure and Ji, 2008; Loman et al., 2012; Wang et al., 2014a,b). Fortunately, a major simplification can be achieved if haploid plants can be raised from these species (Germanà, 2011; Li et al., 2013a). Since the successful haploidization of Datura stramonium (Blakeslee et al., 1922), a number of in vitro techniques have been developed to allow the successful generation of haploids from a wide range of species (Maluszynski, 2003; Clarke et al., 2011).

A common haploidization approach is to seek to regenerate plants from non-fertilized female (gynogenesis) or male (androgenesis) gametes by culturing the appropriate explant in vitro (Chen et al., 2011; Clarke et al., 2011; Germanà, 2011). Gynogenesis has proven to be a successful method in a number of species (Muren, 1989; Hansen et al., 1995; Alan et al., 2003; Godbole and Murthy, 2012). In addition to their value for genomic analysis, haploids can also make an important contribution to crop improvement, since they can be used to short-circuit the process of gene fixation which otherwise requires a number of generations of self fertilization (Godbole and Murthy, 2012; Mohammadi et al., 2012). In self-incompatible species such as chrysanthemum, however, achieving fixation via self-fertilization is scarcely possible.

Methylation of the cytosine base [especially methylation of cytosine at position 5 (5-methylcytosine, $5^{\mathrm{m}} \mathrm{C}$ ) ] has been 
recognized as the predominant form of epigenetic modification, and thus is an important determinant of the information content of eukaryotic genomes. A number of transcribed sequences are characterized by having a lower level of cytosine methylation than do silent ones, especially in their promoter region (Chan et al., 2005). Variation with respect to patterns of DNA methylation has been widely exploited to make inferences regarding plant evolution (Rapp and Wendel, 2005; Leitch and Leitch, 2008; Koh et al., 2010), and, in particular, to the consequences of allopolyploidization (Chen, 2007; Wang et al., 2013b, 2014a). Here, an attempt has been made to generate haploid chrysanthemum plants by stimulating the ovules prior to their in vitro culture through the germination of incompatible pollen on the stigma. Changes to the morphology of the resulting haploids and doubled haploids have been documented, and the methylation-sensitive amplification polymorphism (MSAP) platform used to characterize epigenetic changes induced by both the haploidization and chromosome doubling processes.

\section{MATERIALS AND METHODS \\ PLANT MATERIALS AND MOCK POLLINATION}

The chrysanthemum cultivar "Zhongshanzigui" $(2 n=6 x=54)$ was pollinated by the diploid species Argyranthemum frutescens $(2 n=2 x=18)$; both "Zhongshanzigui" and the A. frutescens accession used are maintained by the Chrysanthemum Germplasm Resource Preserving Centre, Nanjing Agricultural University, China $\left(32^{\circ} 05^{\prime} \mathrm{N}, 118^{\circ} 8^{\prime} \mathrm{E}, 58 \mathrm{~m}\right.$ altitude). Bisexual florets were removed from the maternal inflorescence, and the flowers covered with a paper bag at the stage when the stigmas first became visible. Pollination was carried out 2 days later using a fine-haired brush at 10:00-11:00 AM on a sunny day. To track the progress of pollen growth, 10 ligulate flowers were harvested at six, 12, 24, 36, and $48 \mathrm{~h}$ after pollination, and fixed at room temperature in 1:1:18 formalin:glacial acetic acid:70\% ethanol $(\mathrm{v} / \mathrm{v})$. Prior to its microscopic examination, the material was softened by immersion in $1 \mathrm{M} \mathrm{NaOH}$ for $12 \mathrm{~h}$, squashed under a cover slip and visualized by a fluorescence microscope (Sun et al., 2010).

\section{OVULE CULTURE}

Two days after pollination, the ovaries were harvested, surfacesterilized by immersion in $75 \%(\mathrm{v} / \mathrm{v})$ ethanol for $35 \mathrm{~s}$, followed by $10 \% \quad(\mathrm{v} / \mathrm{v}) \quad \mathrm{H}_{2} \mathrm{O}_{2}$ for $15 \mathrm{~min}$ and six rinses in sterile water. The ovules were dissected from the ovaries and placed on Murashige and Skoog (MS) (Murashige and Skoog, 1962) medium ( $\mathrm{pH} 5.8$ ) containing $8.88 \mathrm{mM}$ 6-benzyladenine, $2.68 \mathrm{mM} \alpha$-naphthaleneacetic acid (NAA) (Tang et al., 2009), $3 \%(\mathrm{w} / \mathrm{v})$ sucrose and solidified with $0.7 \%(\mathrm{w} / \mathrm{v})$ agar. The explants were held at $25 \pm 1{ }^{\circ} \mathrm{C}$ under a $16 \mathrm{~h}$ photoperiod provided by cool white fluorescent lamps $\left(30 \mu \mathrm{mol} \mathrm{m} \mathrm{m}^{-2}\right.$ $\left.\mathrm{s}^{-1}\right)$. Regenerating plantlets were transferred to fresh MS medium ( $\mathrm{pH}$ 5.7) containing $0.54 \mathrm{mM} \mathrm{NAA}, 1 \%$ (w/v) sucrose and solidified by $0.7 \%$ agar, where they were maintained until emerging roots had extended to a length of $\sim 1 \mathrm{~cm}$, at which point they were transplanted into a 2:2:1 mixture of perlite, vermiculite and leaf mold, and maintained in a greenhouse.

\section{PLOIDY LEVEL AND ORIGIN EVALUATION}

Meiotic chromosome pairing in $\mathrm{cv}$. "Zhongshanzigui" was monitored in the anthers of immature inflorescences $(6-7 \mathrm{~mm}$ diameter) fixed in Carnoy's solution (three parts 95\% ethanol, one part glacial acetic acid, v/v). The ploidy level of the regenerants was deduced from their somatic chromosome number, as assayed in their root tips. Roots of $\sim 1 \mathrm{~cm}$ in length were held in ice water for 20-24 h, then fixed in Carnoy's solution and stored at $4^{\circ} \mathrm{C}$ for $24 \mathrm{~h}$. Both anthers and root tips were squashed in a drop of $45 \%$ acetic acid and the mitotic chromosomes were visualized using phase contrast microscopy.

The genomic constitution of the regenerants was assessed via microsatellite genotyping. Genomic DNA was isolated from fully expanded 9th and 10th leaves (counting from the apex) using a modified CTAB method (Porebski et al., 1997). The eight informative primer pairs used are detailed in Table 1. Each PCR comprised an initial denaturation of $95^{\circ} \mathrm{C} / 5 \mathrm{~min}$, followed by seven cycles of $94^{\circ} \mathrm{C} / 45 \mathrm{~s}, 68^{\circ} \mathrm{C} / 45 \mathrm{~s}$ (decreasing by $2^{\circ} \mathrm{C}$ per cycle), $72^{\circ} \mathrm{C} / 60 \mathrm{~s}$, then $30 \mathrm{cycles}$ of $94^{\circ} \mathrm{C} / 45 \mathrm{~s}, 54^{\circ} \mathrm{C} / 45 \mathrm{~s}, 72^{\circ} \mathrm{C} / 60 \mathrm{~s}$, and finally an extension step of $72^{\circ} \mathrm{C} / 5 \mathrm{~min}$. The resulting amplicons were separated by electrophoresis through a $6 \%(\mathrm{w} / \mathrm{v})$ polyacrylamide gel and visualized by silver staining (Wang et al., 2013a).

\section{CHROMOSOME DOUBLING}

Doubled haploids were induced by colchicine treatment. A set of 80 nodal segments harvested from a 1 month old in vitro cultured haploid plantlet were immersed in $500 \mathrm{mg} / \mathrm{L}$ colchicine for $48 \mathrm{~h}$ (Liu et al., 2011), then rinsed four times in sterile water and cultured for 30 days on solidified ( $0.7 \%$ agar) MS medium ( $\mathrm{pH}$ 5.8) containing $3.0 \%(\mathrm{w} / \mathrm{v})$ sucrose. At the end of this period, the material was transferred to a rooting medium (solidified MS supplemented with $0.54 \mathrm{mM}$ NAA, $1 \%$ sucrose, $\mathrm{pH}$ 5.7) and maintained for 60 days at $25 \pm 1{ }^{\circ} \mathrm{C}$ under a $16 \mathrm{~h}$ photoperiod provided by cool white fluorescent lamps $\left(30 \mu \mathrm{mol} \mathrm{m} \mathrm{m}^{-2} \mathrm{~s}^{-1}\right)$.

Table 1 | Sequences of primers used for microsatellite fingerprinting.

\begin{tabular}{ll}
\hline Primers ID & Sequence $\mathbf{( 5}^{\prime} \mathbf{-} \mathbf{3}^{\prime} \mathbf{)}$ \\
\hline $5-\mathrm{F}$ & AAGAAGAACACCAACGCACC \\
$5-\mathrm{R}$ & CAGAACCTGCACGCATTCTA \\
$7-\mathrm{F}$ & AAACGTGGTTTGCTGAAAGG \\
$7-\mathrm{R}$ & ATTGGGCAAACATCAAAAGC \\
$9-\mathrm{F}$ & AGCCAGGGTGTTGAAAATTG \\
$9-\mathrm{R}$ & ATCAGTCACCCCACTCGAAC \\
$21-\mathrm{F}$ & GTTCGCCGCTAAACAAAAAC \\
$21-\mathrm{R}$ & GGGATTGGATTTCAAGGGAT \\
$34-\mathrm{F}$ & CCTAGTATCAAAGCTGCGAACA \\
$34-\mathrm{R}$ & CAATCGCGTTATCGTGTACC \\
$52-\mathrm{F}$ & AGTGACCCGAGCCAGATAGA \\
$52-\mathrm{R}$ & CCGACAAATCATTTCCGTCT \\
$53-\mathrm{F}$ & TCGAAGACAATCAGCACCTG \\
$53-\mathrm{R}$ & TAAGTGTTCTTCCAGCGCCT \\
$77-\mathrm{F}$ & AGGAGGACAATTCGTGCAAC \\
$77-\mathrm{R}$ & CCGTATACCACCAATACAAATACA \\
\end{tabular}


Finally, the plantlets were transplanted into soil and raised in a greenhouse.

\section{MORPHOLOGICAL CHARACTERIZATION}

Ten individual plants were employed for morphological characterization. Plant height and various flower and leaf traits were recorded. An inflorescence diameter index was calculated, and the number of ligulate florets and tubular florets was averaged from a sample of 10 inflorescences (Li, 1993). Leaf length and width were mesaured for the fifth leaf below the shoot apex and average was calaculated from a sample of 10 plants. The length and width of the stomata were measured using an eyepiece micrometer, again from a sample of 10 leaves. Pollen fertility was determined by monitoring germination by a fluorescence microscope after an $8 \mathrm{~h}$ incubation at $20^{\circ} \mathrm{C}$ on an optimized medium composed of $\mathrm{ME}_{3}, 0.1 \mathrm{~g} / \mathrm{L} \mathrm{H}_{3} \mathrm{BO}_{3}, 0.3 \mathrm{~g} / \mathrm{L}$ $\mathrm{CaCl}_{2} \cdot 2 \mathrm{H}_{2} \mathrm{O}$, and $200 \mathrm{~g} / \mathrm{L}$ PEG4000 (Li et al., 2009). Mean germination rates were calculated from three replicates of at least 100 pollen grains. The resulting data were statistically analyzed using SPSS v17.0 software (SPSS, Chicago, IL, USA). An analysis of variance was conducted, employing the Tukey test to identify means which differed significantly from one another.

\section{MSAP ANALYSIS}

The DNA was subjected to MSAP analysis (Vos et al., 1995; Benhattar and Clement, 2004; Roberts et al., 2007), using as adaptors and primers the sequences shown in Table 2. The selective amplification reactions were based on one of 30 primer combinations (E2+HM3/6/7/8, E3+HM3/8, E4+HM2/3/6/7/8, $\mathrm{E} 5+\mathrm{HM} 1 / 2 / 7 / 8, \quad \mathrm{E} 6+\mathrm{HM} 1 / 2 / 6 / 8, \quad \mathrm{E} 7+\mathrm{HM} 1 / 3 / 6 / 7 / 8, \quad$ and E8+HM1/2/3/6/7/8, where E indicates EcoR I and HM Hpa II or Msp I). Meanwhile, two randomly selected plants per line were analyzed with a sub-group of the most informative primer combinations (Wang et al., 2013b, 2014a) to determine whether differences in cytosine methylation profile existed between biological replicates. The amplicons were separated by denaturing polyacrylamide gel electrophoresis and detected by silver staining, following Vos et al. (1995). Fragments were scored as present/absent, and only considered if they were reproducible across two independent PCRs. A statistical analysis of differences between the parent and each of the derivatives ( $U$-values) was based on the suggestion of Wang et al. (2014a):

$p=\frac{\mathrm{y} 1+\mathrm{y} 2}{n 1+n 2} ; q=1-p ; \delta_{p 1-p 2}=\sqrt{p q\left(\frac{1}{n 1}+\frac{1}{n 2}\right)} ; U=\frac{p 1-p^{2}}{\delta_{p 1-p 2}}$

where $\mathrm{n} 1$ represents the total number of fragments of a given sample, $\mathrm{n} 2$ the total fragments of another sample, y1 the total number of methylated fragments of a given sample values, y2 the total number of methylated fragments in another sample, $\mathrm{p} 1$ the proportion (\%) of methylated fragments of a given sample values and p 2 the proportion (\%) of methylated fragments in another sample.
Table 2 | Sequences of adaptors and primers used for MSAP analysis.

\begin{tabular}{|c|c|}
\hline Adaptors/primers & Sequence $\left(5^{\prime}-3^{\prime}\right)$ \\
\hline EcoR I adaptor-1 & CTCGTAGACTGCGTACC \\
\hline EcoR I adaptor-2 & AATTGGTACGCAGTCTAC \\
\hline Hpa II/Msp I adaptor-1 & GATCATGAGTCCTGCT \\
\hline Hpa II/Msp I adaptor-2 & CGAGCAGGACTCATGA \\
\hline EcoR I pre-selective primer & GACTGCGTACCAATTCA \\
\hline Hpa II/Msp I pre-selective primer & ATCATGAGTCCTGCTCGG \\
\hline EcoR I selective primer-2 & GACTGCGTACCAATTCAAG \\
\hline EcoR I selective primer-3 & GACTGCGTACCAATTCACA \\
\hline EcoR I selective primer-4 & GACTGCGTACCAATTCACT \\
\hline EcoR I selective primer-5 & GACTGCGTACCAATTCACC \\
\hline EcoR I selective primer-6 & GACTGCGTACCAATTCACG \\
\hline EcoR I selective primer-7 & GACTGCGTACCAATTCAGC \\
\hline EcoR I selective primer-8 & GACTGCGTACCAATTCAGG \\
\hline Hpa II/Msp I selective primer-1 & ATCATGAGTCCTGCTCGGTAA \\
\hline Hpa II/Msp I selective primer-2 & ATCATGAGTCCTGCTCGGTCC \\
\hline Hpa II/Msp I selective primer-3 & ATCATGAGTCCTGCTCGGTTC \\
\hline Hpa II/Msp I selective primer-6 & ATCATGAGTCCTGCTCGGTAG \\
\hline Hpa II/Msp I selective primer-7 & ATCATGAGTCCTGCTCGGTTG \\
\hline Hpa II/Msp I selective primer-8 & ATCATGAGTCCTGCTCGGTCA \\
\hline
\end{tabular}

\section{RESULTS}

\section{POLLEN GERMINATION AND CALLUS INDUCTION FROM OVULES}

No pollen tube formation was detected over the period from 6 to $48 \mathrm{~h}$ post pollination (Figures 1A-E). From 2579 ovules only 105 produced any callus after 20 days in culture (Figure 1F). The calli became green, had a rough surface and were variable in size (Figure 1G), but only three of them went on to develop a somatic embryo: the first after 62 days in culture, the second after 68 days and the final one after 133 days (Figure 1H).

\section{PLOIDY AND ORIGIN OF THE REGENERATED PLANTS AND DERIVED DOUBLED HAPLOIDS}

Meiotic analysis of "Zhongshanzigui" confirmed it as a diploidized allohexaploid (Figures 2A-C), with the expected chromosome number of $2 n=6 x=54$. The three regenerated plantlets all developed into adult plants and reached flowering. On the basis of their somatic chromosome number, only one was a true haploid $(2 n=3 x=27)$ (Figure 2D), whereas the other two were both hexaploid $(2 n=6 x=54)$. The true haploid regenerated much later than the other two, and was also the slowest growing of the three regenerants.

Microsatellite profiling of the three regenerants indicated that two hexaploid ones score the same microsatellite fragments, while the true haploid has fewer ones (Figure 3). The implication was each was derived from a somatic (rather than from a gametic) cell of the mother plant, and represented the product of a spontaneous whole genome doubling during the in vitro culture process. Following colchicine treatment, nine doubled haploid plants (Figure 2E), each bearing the expected chromosome complement, were derived from the cultured nodal segments of the confirmed haploid. 


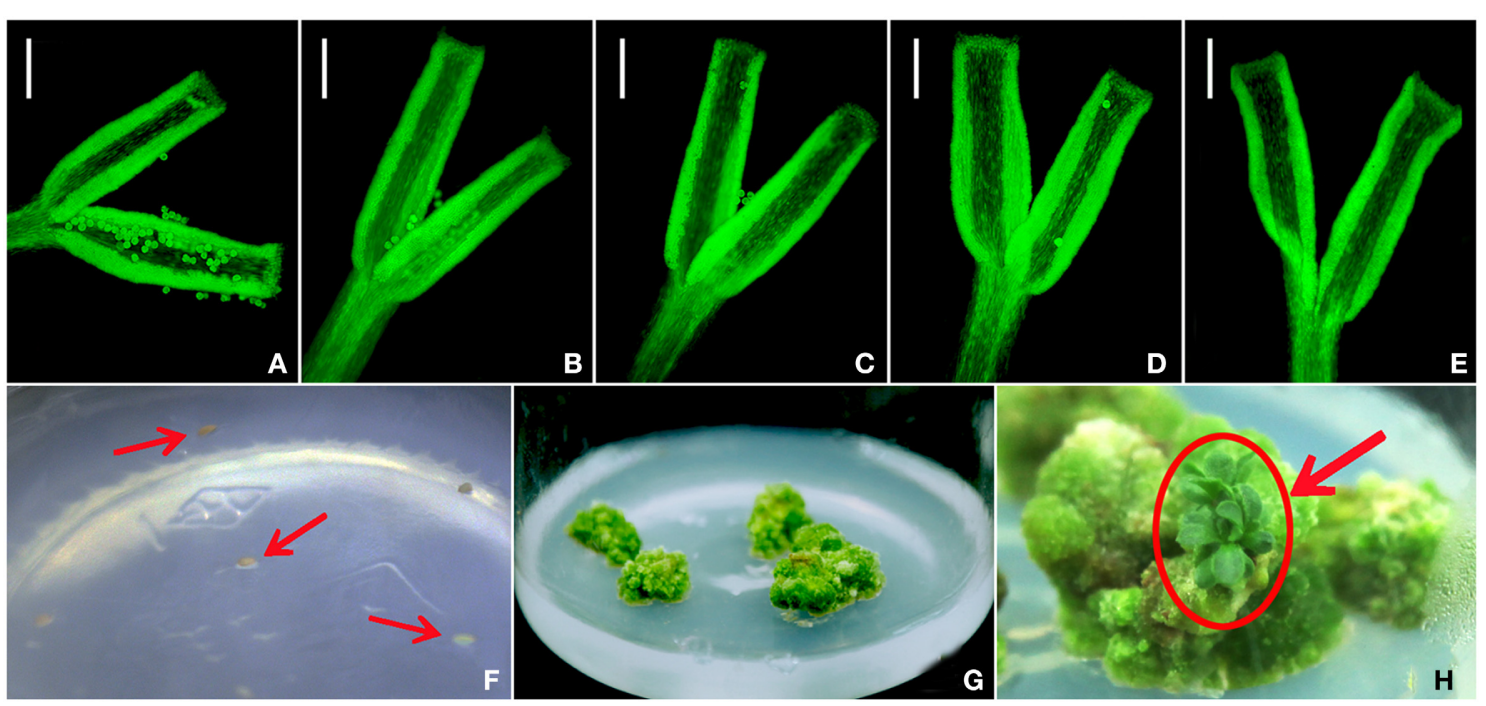

FIGURE 1 | The germination of $A$. frutescens pollen on the $C$. morifolium stigma imaged at (A) $6 \mathrm{~h},(\mathrm{~B}) 12 \mathrm{~h},(\mathrm{C}) 24 \mathrm{~h}$, (D) $36 \mathrm{~h}$, and (E) $48 \mathrm{~h}$ post pollination and callus development from non-fertilized, in vitro cultured $\boldsymbol{C}$. morifolium ovules. (F) ovules, (G) formation of callus, (H) formation of plantlets. Bar (A-E): $100 \mu \mathrm{m}$.

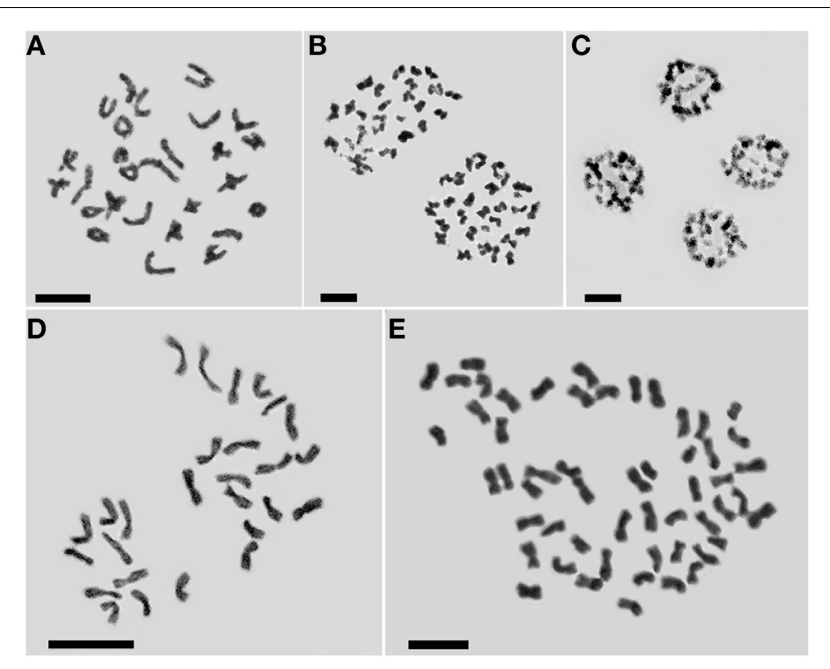

FIGURE 2 | Cytological characterization of $C$. morifolium cv. "Zhongshanzigui" and its haploid and doubled haploid derivatives. (A-C) Meiotic chromosomes in the cV. "Zhongshanzigui" pollen mother cell: (A) metaphase I, (B) anaphase I, (C) telophase II. Somatic chromosomes in (D) haploid and (E) doubled haploid plants. Bar: $5 \mu \mathrm{m}$.

\section{MORPHOLOGY OF THE HAPLOID AND DERIVED DOUBLED HAPLOID PLANTS}

Both the mother and the doubled haploid plants grew more vigorously than did the haploid plant, and formed larger plants at the adult stage (Figure 4, Table 3). The mean plant height of "Zhongshanzigui" was $89 \mathrm{~cm}$, almost three times that of the haploid. The colchicine-doubled plants were taller than their haploid progenitor, but still only grew to half the height of "Zhongshanzigui." Similarly, the leaf length, leaf width and flower diameter of "Zhongshanzigui" plants were all larger than their equivalents in the doubled haploids, which were in turn larger than those of the haploid (Figures 4A-E). The "Zhongshanzigui" inflorescence formed 177 tubular florets, compared to 96 in the haploid and 151 in the doubled haploids. Ligulate flower number was less variable: the number borne by the haploid inflorescence was greater than that by the doubled haploid inflorescence, but smaller than that by the "Zhongshanzigui" inflorescence (Figure 4D, Table 3). Interestingly, the color of the "Zhongshanzigui" inflorescence was mauve, while that of the haploid and doubled haploids was yellow (Figure 4D). The haploid's stomatal length was shorter than those of either "Zhongshanzigui" or the doubled haploids (Figures 4F-H). In vitro cultured pollen began to germinate within $2 \mathrm{~h}$ (data not shown), and by $8 \mathrm{~h} 17.0 \%$ of the "Zhongshanzigui" pollen had germinated; the proportion in the doubled haploids was $9.7 \%$, while in the haploid it was only $1.3 \%$. The pollen tubes formed by the few germinating grains of the latter plant were twisted and short, unlike those of the doubled haploids (Figures 4I-K).

\section{CHANGES OF CYTOSINE METHYLATION IN THE HAPLOID AND DOUBLED HAPLOID PLANTS}

MSAP profiling was based on an isoschizomeric pair of restrictions enzymes, where one cleaves irrespective of the methylation status at the recognition sequence, while the other only cleaves when the recognition site is unmethylated. The enzyme pair Msp I and Hpa II are particularly suitable, as their recognition sequence ( $5^{\prime}$-CCGG-3') includes a CpG dinucleotide. The latter does not cleave if either cytosine is fully methylated, but will do so if the external cytosine is hemi-methylated (CpCpG methylated, only one DNA strand methylated); in contrast, Msp I will not cleave if the external cytosine is fully- or hemi-methylated; the both eazymes do not cleave if the both cytosines fully methylated (McClelland et al., 1994; Sha et al., 2005). Therefore MSAP based on Hpa II and Msp I cleavage can discriminate four kinds of methylation state: Type I is non-methylated site, 


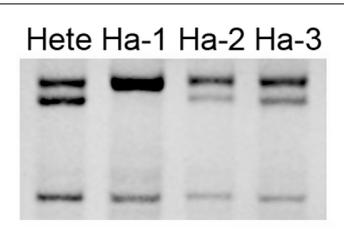

Primer pairs \# 5

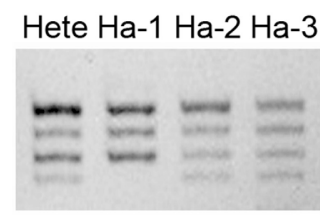

Primer pairs \# 34

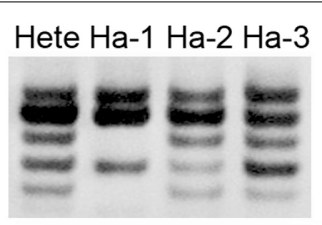

Primer pairs \# 7

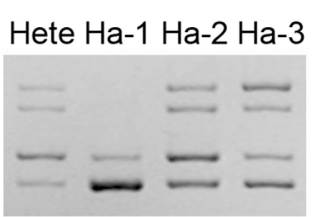

Primer pairs \# 52

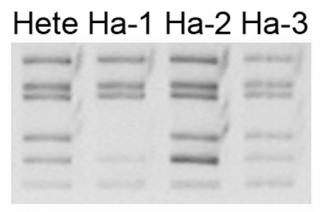

Primer pairs \# 9

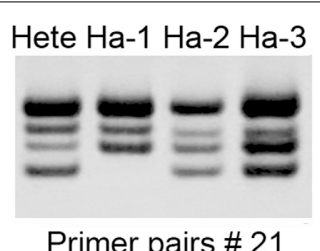

Primer pairs \# 21

FIGURE 3 | Microsatellite fingerprinting reveals the genomic constitution of the regenerants from ovule culture. Hete is cv. "Zhongshanzigui," Ha-1 is a true haploid; Ha-2 and Ha-3 originate from somatic maternal tissue.

Type II is fully-methylated or CpG methylated site; Type III is hemi-methylated or CpCpG methylated site; Type IV is hypermethylated site (Figure 5A).

Applying the full set of 30 MSAP primer combinations identified 1008 fragments. Of these, $52.2 \%$ were methylated in the "Zhongshanzigui" genome, $47.0 \%$ in the haploid's and $51.7 \%$ in the doubled haploids'. A higher $U$-value implies a larger difference between different samples, but only $U$-value $>1.96\left[U_{(0.05)}=\right.$ 1.96] was statistically significant. The $U$-value of the haploid with respect to "Zhongshanzigui" was 2.30 , while it was 2.02 between the haploid and the doubled haploids. The difference between "Zhongshanzigui" and the doubled haploids was statistically insignificant $(U=0.24)$ (Figure 5B). It should be noted that each pair of biological replicates manifested a near-complete uniformity in MSAP profile, as did all nine of the doubled haploids (Supplementary Figure 1); thus, chromosome doubling might be a highly conservative process with respect to cytosine methylation.

Specifically, most, but not all of the MSAP fragments in the "Zhongshanzigui" profile were shared by the haploid's and the doubled haploids'. As a result of haploidization of cv. "Zhongshanzigui," of the 94 fragments which varied for cytosine methylation status between the haploid and the maternal cultivar, $35(37 \%)$ were methylated in the former: 26 involved hemimethylation, eight full methylation and one hyper-methylation. The other 59 (63\%) fragments were demethylated in the haploid, 47 switching from hemi-methylation, nine from full methylation and three from hyper-methylation. Following the chromosome doubling of the haploid, of these, $70(73 \%)$ became methylated in the doubled haploids ( 32 changed from hemi-methylated and 20 from non-methylated), while 18 moved from non-methylated to hyper-methylated. The chromosome doubling induced demethylation in 26 fragments, of which seven changed from hyper-methylated to non-methylated and 19 sites from hemi- or fully-methylated to non-methylated. As a whole, the frequency of demethylation was 1.69-fold that of methylation as induced by haploidization. While from haploid to double haploid, the frequency of demethylation was only 0.38 -fold of the frequency of methylation.

\section{DISCUSSION}

\section{INDUCTION OF HAPLOIDY IN C. MORIFOLIUM}

Attempts to induce chrysanthemum haploids from either immature anthers or microspores have been largely unsuccessful to date; although regenerants have been reported, their somatic chromosome number proved to be the same as that of the progenitor plant (Yang et al., 2005). Prior unpublished experiments conducted in our laboratory have similarly failed to yield haploids, whether the protocol was based on either isolated microspores or non-stimulated ovules. In other species, both haploids and doubled haploids have been induced from non-fertilized ovule explants (Chen et al., 2011). The pre-treatment of the explant by germinating incompatible pollen on the stigma, as implemented in the current study, can be an effective means of increasing the likelihood of recovering haploid plants, as shown for a range of Japanese Chrysanthemum species (Watanabe, 1977; Wędzony et al., 2009), saffron, sugar beet and carnation (Gürel et al., 2000; Sato et al., 2000; Sulistyaningsih et al., 2006). Nevertheless, from a total of over 2500 cultured, pre-treated ovules, only three plants were successfully regenerated, and of these just one was a true haploid, whereas the remaining two regenerants were both allohexaploid and should be derived from heterozygous somatic cell (Figure 3). Clearly, improvements will need to be made to the haploidization protocol before haploid recovery can be considered routine in chrysanthemum.

Where spontaneous chromosome doubling is rare, colchicine treatment can provide a ready means for its induction ( $\mathrm{Li}$ et al., 2013a). Cytogenetic analysis has shown that the present results are in good agreement with previous studies on the colchicine treatment of plants or plantlets (Chen et al., 2011; Li et al., 2013b). Apart from the direct identification of ploidy obtained via karyotypic analysis, plant morphology, in the form of plant height, leaf size, flower diameter and stomatal length were all usable here to distinguish between haploid and doubled haploid plants. The haploid grew less vigorously than the mother cultivar; its only advantage over the diploid form related to the number of ligulate flowers developed in the inflorescence. Surprisingly, the color of both the haploid's and the doubled haploids' inflorescence was yellow rather than mauve, which may be due to expressions 

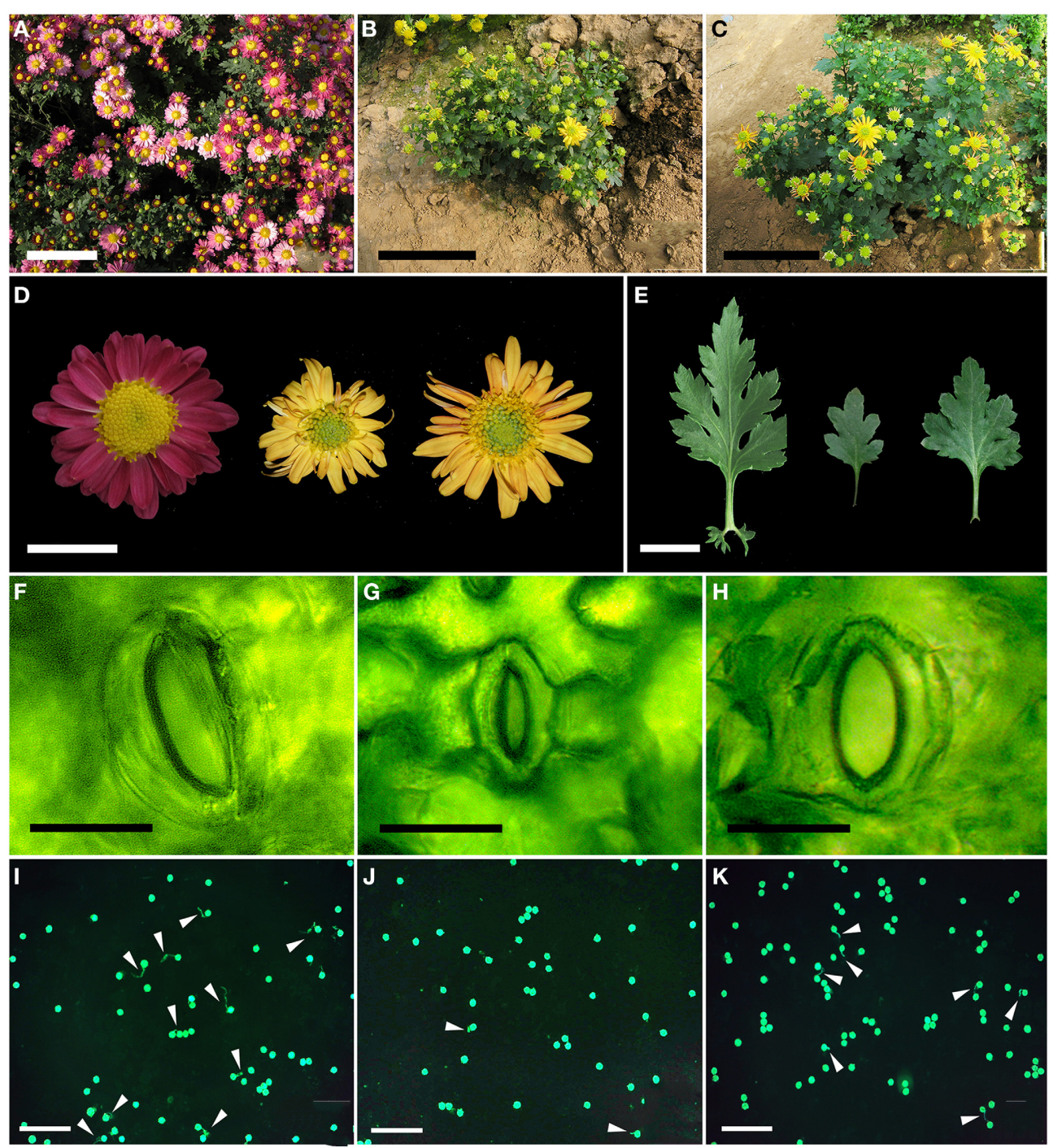

FIGURE 4 | Whole plant morphology of (A) cv. "Zhongshanzigui," (B) the haploid, and (C) the doubled haploid plants. Bar: $10 \mathrm{~cm}$. (D) Leaf morphology of cv. "Zhongshanzigui" (left), the haploid (center) and the doubled haploid (right) plants. Bar: $2 \mathrm{~cm}$. (E) Flower morphology of cv. "Zhongshanzigui" (left), the haploid (center) and the doubled haploid (right) plants. Bar: $2 \mathrm{~cm}$. (F-H) Stomatal morphology of (F) $\mathrm{cV}$. "Zhongshanzigui," (G) the haploid and (H) doubled haploid plants. Bar: $30 \mu \mathrm{m}$. (I-K) Pollen viability of (I) cV. "Zhongshanzigui," (G) the haploid and $(\mathbf{K})$ doubled haploid plants. Arrows point to the pollen tubes. Bar: $200 \mu \mathrm{m}$.

Table 3 | The morphology of "Zhongshanzigui" and its derived haploid and doubled haploid progeny

\begin{tabular}{lrrr}
\hline Characters & Heterozygote & Haploid & Di-haploid \\
\hline Plant height $(\mathrm{cm})$ & $89.33 \pm 3.98^{\mathrm{a}}$ & $28.42 \pm 2.25^{\mathrm{c}}$ & $3.66 \pm 0.25^{\mathrm{c}}$ \\
Leaf length $(\mathrm{cm})$ & $7.83 \pm 0.31^{\mathrm{a}}$ & $2.29 \pm 0.20^{\mathrm{c}}$ & $6.07 \pm 0.36^{\mathrm{b}}$ \\
Leaf width $(\mathrm{cm})$ & $4.76 \pm 0.23^{\mathrm{a}}$ & $33.40 \pm 1.35^{\mathrm{b}}$ & $3.36 \pm 0.17^{\mathrm{b}}$ \\
Ligulate flower quantity & $44.30 \pm 0.95^{\mathrm{a}}$ & $96.00 \pm 1.89^{\mathrm{c}}$ & $27.70 \pm 2.41^{\mathrm{c}}$ \\
Tubular florets quantity & $176.80 \pm 5.09^{\mathrm{a}}$ & $3.15 \pm 0.20^{\mathrm{c}}$ & $3.96 \pm 0.35^{\mathrm{b}}$ \\
Flower diameter $(\mathrm{cm})$ & $4.36 \pm 0.33^{\mathrm{a}}$ & $33.60 \pm 1.56^{\mathrm{c}}$ & $38.93 \pm 1.40^{\mathrm{b}}$ \\
Stomata length $(\mu \mathrm{m})$ & $43.71 \pm 1.35^{\mathrm{a}}$ & $1.27 \% \pm 0.35^{\mathrm{c}}$ &
\end{tabular}

Values (mean $\pm S E$ ) associated with a different superscript $(a, b, c)$ differ significantly from one another $(p<0.01)$. 


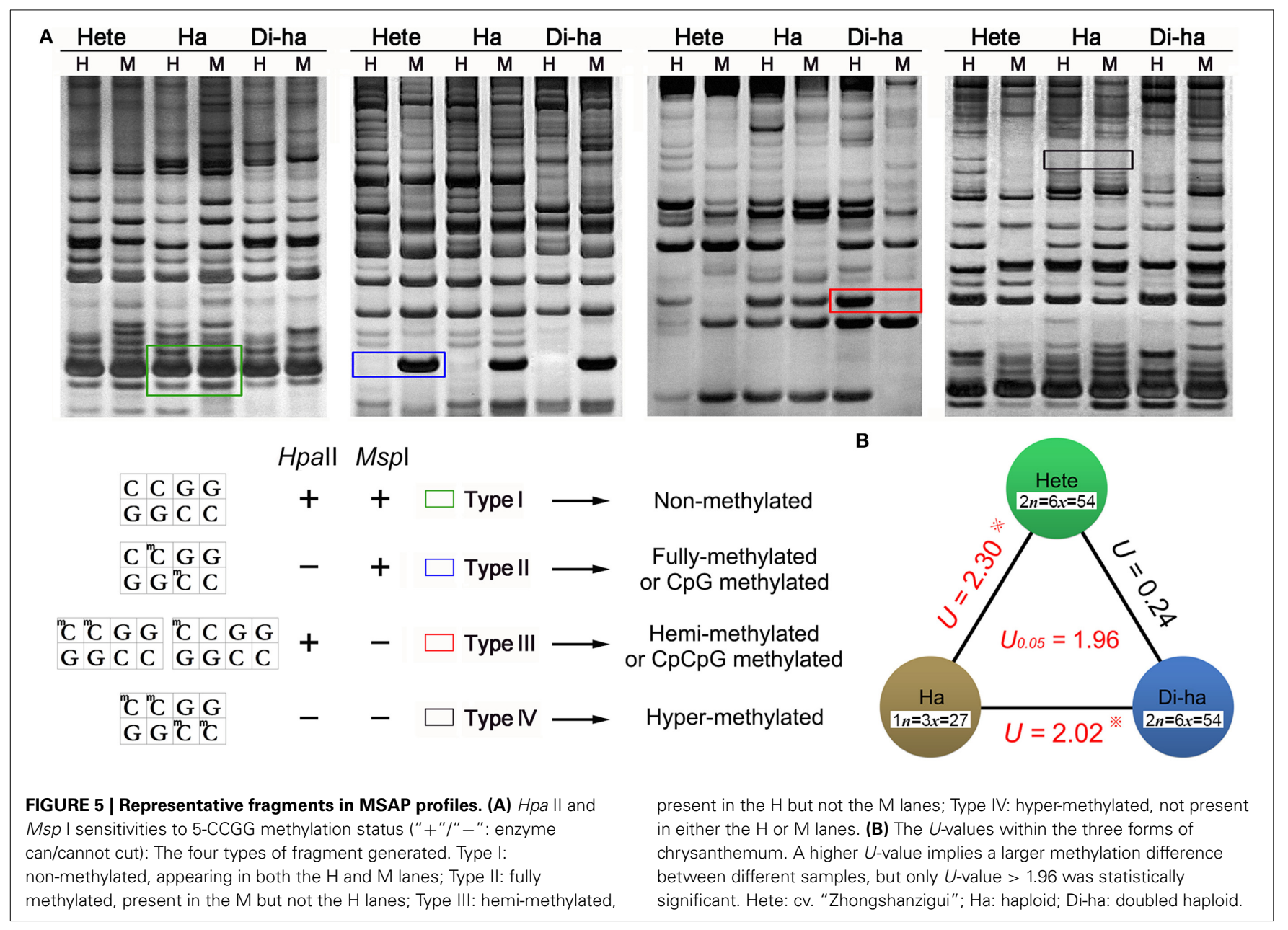

of some recessive genes gene(s) involved in regulating flower color.

\section{VARIATION OF CYTOSINE METHYLATION IN HETEROZYGOTE, HAPLOID AND DI-HAPLOID}

The MSAP profiling showed that the haploid experienced a significantly lower frequency of cytosine methylation than did either the maternal diploid $(U=2.30)$ or the doubled haploid $(U=$ 2.02 ), but that there was no significant difference in frequency between the diploid and the doubled haploids $(U=0.24)$. It is possible, of course, that some variation in heritable cytosine methylation may have been induced during the callus phase (Miguel and Marum, 2011), but it is impossible to precisely quantify this source of variation. For this reason, it is difficult to precisely quantify the severity of this change caused by the tissue culture step. However, it reported that changes in cytosine methylation caused by tissue culture are thought to be rare in Codonopsis lanceolata (Guo et al., 2007), while in oil palm, the frequency of this event is low $(\sim 0.3 \%)$ (Matthes et al., 2001). In rice, such changes have been shown to be concentrated within a relatively small proportion of the genome using whole genome bisulfite sequencing (Stroud et al., 2013). All these studies indicated that haploidization rather than the tissue culture step may play the major role in altering methylation in these chrysanthemum lines.

The influence of polyploidization on epigenetic status has been studied in some detail in the allotetraploid synthesized from the interspecific hybrid Arabidopsis thaliana $x$ A. lyratara. In this system, Beaulieu et al. (2009) used an MSAP platform to show that around $25 \%$ of MSAP fragments suffered a change in their cytosine methylation status, frequency which contrasts to the figure of just $\sim 9 \%$ figure which applied to the comparison between "Zhongshanzigui" and its haploid (or doubled haploid) derivatives. It is recognized that any potential CpG sites present in the heterozygous state in "Zhongshanzigui" may not have been inherited by the haploid following segregation, thus producing an over-estimate of the actual number of de-methylation events; however, even so the frequency of de-methylation was still 1.7 times that of methylation. The implication is that haploidization favors de-methylation. Some adjustments in DNA methylation were clearly induced by the chromosome doubling process, but here it was methylation which was favored. The MSAP data implied that globally, methylation was about 2.7-fold more frequent than de-methylation.

Hyper-methylation tends to be associated with gene silencing, and hypo-methylation with gene activation (Martienssen and Colot, 2001; Wang et al., 2006). Cytosine methylation has been documented as having a marked effect on cell differentiation, chromatin inactivation and genomic imprinting and is known to 
be affected by chromosome doubling (Finnegan, 2001, 2002; Liu and Wendel, 2003). As an example, among $F_{1}$ hybrids between diploid species in the genera Aegilops and Triticum group, an estimated $13 \%$ of genes suffered cytosine methylation as a result of genomic shock (Shaked et al., 2001), a 2-fold difference was observed in the level of cytosine methylation between reciprocal $\mathrm{F}_{1}$ interspecific Cucumis spp. hybrids and their allotetraploid, with $68 \%$ of sites becoming cytosine methylated and $32 \%$ becoming de-methylated in the allotetraploid (Chen et al., 2007). Here, about $9 \%$ of the sites were variable, and of these, $37 \%$ became methylated as a result of haploidization and $73 \%$ as a result of whole genome duplication. The expectation was therefore that evidence would be found for alterations in cytosine methylation and have had a potential influence on the haploid and double haploid chrysanthemum plants.

Notably, in angiosperm female gametogenesis only half of the endogenous sequences or genes present in the heterozygotes will be present in the haploids. The difference in chromosomal constitution between parental cultivar and haploids might have an effect on gene expression, cell differentiation, chromatin inactivation and genomic imprinting via positive or passive demethylation of their DNA (Saze et al., 2003; Henderson and Jacobsen, 2007). This may be the reason the haploid displayed a high $U$-value (2.30) compared with cv. "Zhongshanzigui" (Figure 5B). Moreover, the original epigenetic makeup of the cultivar was restored in our hands in the doubled haploid via whole-genome duplication with no significant $(U=0.24)$ between $\mathrm{cv}$. "Zhongshanzigui" and doubled haploids (Figure 5B). It could therefore be hypothesized that this alteration may secure appropriate maintenance as well as flexibility of epigenetic determination within three forms of chrysanthemum. Even though there was no significant difference (52.2 vs. 51.7\%) between the frequency of methylated MSAP fragments in "Zhongshanzigui" and the doubled haploids, their detailed pattern of methylation was different, accounting perhaps in part for the differences in phenotype between them.

\section{IN CONCLUSION}

The present study represents the first report of the production of haploid and doubled haploid chrysanthemum plants derived from the in vitro culture of non-fertilized ovules, morphological traits were changed significantly in the haploid plants. MSAP profiling suggested that alterations in cytosine methylation occurred as a result of both the haploidization and the chromosome doubling processes.

\section{AUTHOR CONTRIBUTIONS}

Conceived and designed the experiments: Haibin Wang, Fadi Chen, Jiafu Jiang, Sumei Chen. Performed the experiments: Haibin Wang, Fadi Chen, Jiafu Jiang. Analyzed the data: Haibin Wang, Bin Dong. Contributed reagents/materials/analysis tools: Weimin Fang, Zhiyong Guan. Wrote the paper: Haibin Wang, Jiafu Jiang, Sumei Chen. All authors read and approved the final manuscript.

\section{ACKNOWLEDGMENTS}

This research was supported by the National Natural Science Foundation of China $(31272203,31272196,31372092$, 31370699,
31372100), the Program for New Century Excellent Talents in University of Chinese Ministry of Education (NCET-12-0890), the Fund for Independent Innovation of Agricultural Sciences in Jiangsu Province [CX(12)2020], the Program for Hi-Tech Research, Jiangsu, China (BE2012350), and A Project Funded by the Priority Academic Program Development of Jiangsu Higher Education Institutions.

\section{SUPPLEMENTARY MATERIAL}

The Supplementary Material for this article can be found online at: http://www.frontiersin.org/journal/10.3389/fpls.2014.00738/ abstract

\section{Supplementary Figure 1 | Examples of MSAP profiles implying cytosine} methylation alterations between biological replicates. The Hpall lanes involve the primer combination E4+HM7, and the Mspl lanes E8+HM8. Hete: "Zhongshanzigui"; Ha: haploid; Di-ha: doubled haploid. Two individual plants from each line (one marked with an asterisk, the other not) were selected at random.

\section{REFERENCES}

Alan, A. R., Mutschler, M. A., Brants, A., Cobb, E., and Earle, E. D. (2003). Production of gynogenic plants from hybrids of Allium cepa L. and A. roylei Stearn. Plant Sci. 165, 1201-1211. doi: 10.1016/S0168-9452(03)00327-3

Benhattar, J., and Clement, G. (2004). Methylation-sensitive single-strand conformation analysis: a rapid method to screen for and analyze DNA methylation. Methods Mol. Biol. 287, 181-193. doi: 10.1385/1-59259-828-5:181

Blakeslee, A. F., Belling, J., Farnham, M., and Bergner, A. D. (1922). A haploid mutant in the jimson weed, "datura stramonium." Science 55, 646. doi: 10.1126/science.55.1433.646

Beaulieu, J., Jean, M., and Belzile, F. (2009). The allotetraploid Arabidopsis thaliana-Arabidopsis lyrata subsp. petraea as an alternative model system for the study of polyploidy in plants. Mol. Genet. Genom. 281, 421-435. doi: 10.1007/s00438-008-0421-7

Chan, S. W., Henderson, I. R., and Jacobsen, S. E. (2005). Gardening the genome: DNA methylation in Arabidopsis thaliana. Nat. Rev. Genet. 6, 351-360. doi: 10.1038/nrg1601

Chandler, S. F., and Sanchez, C. (2012). Genetic modification; the development of transgenic ornamental plant varieties. Plant Biotechnol. J. 10, 891-903. doi: 10.1111/j.1467-7652.2012.00693.x

Chen, J. F., Cui, L., Malik, A. A., and Mbira, K. G. (2011). In vitro haploid and dihaploid production via unfertilized ovule culture. Plant Cell Tiss. Org. Cult. 104, 311-319. doi: 10.1007/s11240-010-9874-6

Chen, L., Lou, Q., Zhuang, Y., Chen, J., Zhang, X., and Wolukau, J. N. (2007). Cytological diploidization and rapid genome changes of the newly synthesized allotetraploids Cucumis x hytivus. Planta 225, 603-614. doi: 10.1007/s00425006-0381-2

Chen, Z. J. (2007). Genetic and epigenetic mechanisms for gene expression and phenotypic variation in plant polyploids. Annu. Rev. Plant Biol. 58, 377-406. doi: 10.1146/annurev.arplant.58.032806.103835

Clarke, H. J., Kumari, M., Khan, T. N., and Siddique, K. H. (2011). Poorly formed chloroplasts are barriers to successful interspecific hybridization in chickpea following in vitro embryo rescue. Plant Cell Tiss. Org. Cult. 106, 465-473. doi: 10.1007/s11240-011-9944-4

Finnegan, E. J. (2001). Is plant gene expression regulated globally? Trends Genet. 17, 361-365. doi: 10.1016/S0168-9525(01)02319-8

Finnegan, E. J. (2002). Epialleles - a source of random variation in times of stress. Curr. Opin. Plant Biol. 5, 101-106. doi: 10.1016/S1369-5266(02)00233-9

Gürel, S., Gürel, E., and Kaya, Z. (2000). Doubled haploid plant production from unpollinated ovules of sugar beet (Beta vulgaris L.). Plant Cell Rep. 19, 1155-1159. doi: 10.1007/s002990000248

Germanà, M. A. (2011). Anther culture for haploid and doubled haploid production. Plant Cell Tiss. Org. Cult. 104, 283-300. doi: 10.1007/s11240-010-9852-z

Godbole, M., and Murthy, H. N. (2012). Parthenogenetic haploid plants using gamma irradiated pollen in snapmelon (Cucumis melo var. momordica). Plant Cell Tiss. Org. Cult. 109, 167-170. doi: 10.1007/s11240-011-0066-9 
Guo, W., Wu, R., Zhang, Y., Liu, X., Wang, H., Gong, L., et al. (2007). Tissue cultureinduced locus-specific alteration in DNA methylation and its correlation with genetic variation in Codonopsis lanceolata Benth. et Hook. f. Plant Cell Rep. 26, 1297-1307. doi: 10.1007/s00299-007-0320-0

Hall, C. R., and Dickson, M. W. (2011). Economic, environmental, and health/well-being benefits associated with green industry products and services: a review. J. Environ. Hortic. 29, 96-103. Available online at: http://www.hriresearch.org/docs/publications/JEH/JEH_2011/ JEH_2011_29_2/JEH\%2029-2-96-103.pdf

Hansen, A., Gertz, A., Joersbo, M., and Andersen, S. (1995). Short-duration colchicine treatment for in vitro chromosome doubling during ovule culture of Beta vulgaris L. Plant Breed. 114, 515-519. doi: 10.1111/j.14390523.1995.tb00847.x

Henderson, I. R., and Jacobsen, S. E. (2007). Epigenetic inheritance in plants. Nature 447, 418-424. doi: 10.1038/nature05917

Kearsey, M. (2002). "QTL analysis: problems and (possible) solutions," in Quantitative Genetics, Genomics, and Plant Breeding, ed M. J. Kearsey (Birmingham: CABI Pub), 45-58.

Koh, J., Soltis, P. S., and Soltis, D. E. (2010). Homeolog loss and expression changes in natural populations of the recently and repeatedly formed allotetraploid Tragopogon mirus (Asteraceae). BMC Genomics 11:97. doi: 10.1186/14712164-11-97

Li, H. (1993). Chrysanthemum in China. Nangjing: Jiangsu Scientific and Technical Press.

Li, J. R., Zhuang, F. Y., Ou, C. G., Hu, H., Zhao, Z. W., and Mao, J. H. (2013a). Microspore embryogenesis and production of haploid and doubled haploid plants in carrot (Daucus carota L.). Plant Cell Tiss. Org. Cult. 112, 275-287. doi: 10.1007/s11240-012-0235-5

Li, J., Teng, N. J., Chen, F. D. C., Chen, S. M., Sun, C. Q., and Fang, W. M. (2009). Reproductive characteristics of Opisthopappus taihangensis (Ling) Shih, an endangered Asteraceae species endemic to China. Sci. Horticult. 121, 474-479. doi: 10.1016/j.scienta.2009.02.025

Li, Y., Li, H., Chen, Z., Ji, L. X., Ye, M. X., Wang, J., et al. (2013b). Haploid plants from anther cultures of poplar (Populus $\times$ beijingensis). Plant Cell Tiss. Org. Cult. 114, 39-48. doi: 10.1007/s11240-013-0303-5

Liu, B., and Wendel, J. F. (2003). Epigenetic phenomena and the evolution of plant allopolyploids. Mol. Phylogenet. Evol. 29, 365-379. doi: 10.1016/S10557903(03)00213-6

Liu, S. Y., Chen, S. M., Chen, Y., Guan, Z. Y., Yin, D. M., and Chen, F. D. (2011). In vitro induced tetraploid of Dendranthema nankingense (Nakai) Tzvel. shows an improved level of abiotic stress tolerance. Sci. Horticult. 127, 411-419. doi: 10.1016/j.scienta.2010.10.012

Leitch, A. R., and Leitch, I. J. (2008). Genomic plasticity and the diversity of polyploid plants. Science 320, 481-483. doi: 10.1126/science. 1153585

Loman, N. J., Misra, R. V., Dallman, T. J., Constantinidou, C., Gharbia, S. E., Wain, J., et al. (2012). Performance comparison of benchtop highthroughput sequencing platforms. Nat. Biotechnol. 30, 434-439. doi: 10.1038/ nbt.2198

Maluszynski, M. (2003). Doubled Haploid Production in Crop Plants: A Manual. Dordrecht: Springer.

Martienssen, R. A., and Colot, V. (2001). DNA methylation and epigenetic inheritance in plants and filamentous fungi. Science 293, 1070-1074. doi: 10.1126/science.293.5532.1070

Matthes, M., Singh, R., Cheah, S. C., and Karp, A. (2001). Variation in oil palm (Elaeis guineensis Jacq.) tissue culture-derived regenerants revealed by AFLPs with methylation-sensitive enzymes. Theor. Appl. Genet. 102, 971-979. doi: $10.1007 / \mathrm{s} 001220000491$

McClelland, M., Nelson, M., and Raschke, E. (1994). Effect of site-specific modification on restriction endonucleases and DNA modification methyltransferases. Nucleic Acids Res. 22, 3640-3659. doi: 10.1093/nar/22. 17.3640

Miguel, C., and Marum, L. (2011). An epigenetic view of plant cells cultured in vitro: somaclonal variation and beyond. J. Exp. Bot. 62, 3713-3725. doi: 10.1093/jxb/err155

Mohammadi, P. P., Moieni, A., Ebrahimi, A., and Javidfar, F. (2012). Doubled haploid plants following colchicine treatment of microspore-derived embryos of oilseed rape (Brassica napus L.). Plant Cell Tiss. Org. Cult. 108, 251-256. doi: 10.1007/s11240-011-0036-2
Murashige, T., and Skoog, F. (1962). A revised medium for rapid growth and bio assays with tobacco tissue cultures. Physiol. Plant. 15, 473-497. doi: 10.1111/j.1399-3054.1962.tb08052.x

Muren, R. C. (1989). Haploid plant induction from unpollinated ovaries in onion. Hortscience 24, 833-834.

Porebski, S., Bailey, L. G., and Baum, B. R. (1997). Modification of a CTAB DNA extraction protocol for plants containing high polysaccharide and polyphenol components. Plant Mol. Biol. Rep. 15, 8-15. doi: 10.1007/BF027 72108

Rapp, R. A., and Wendel, J. F. (2005). Epigenetics and plant evolution. New Phytol. 168, 81-91. doi: 10.1111/j.1469-8137.2005.01491.x

Roberts, R. J., Vincze, T., Posfai, J., and Macelis, D. (2007). REBASE-enzymes and genes for DNA restriction and modification. Nucleic Acids Res. 35, D269-D270. doi: 10.1093/nar/gkl891

Sato, S., Katoh, N., Yoshida, H., Iwai, S., and Hagimori, M. (2000). Production of doubled haploid plants of carnation (Dianthus caryophyllus L.) by pseudofertilized ovule culture. Sci. Horticult. 83, 301-310. doi: 10.1016/S03044238(99)00090-4

Saze, H., Scheid, O. M., and Paszkowski, J. (2003). Maintenance of CpG methylation is essential for epigenetic inheritance during plant gametogenesis. Nat. Genet. 34, 65-69. doi: 10.1038/ng1138

Sha, A., Lin, X., Huang, J., and Zhang, D. (2005). Analysis of DNA methylation related to rice adult plant resistance to bacterial blight based on methylationsensitive AFLP (MSAP) analysis. Mol. Genet. Genom. 273, 484-490. doi: 10.1007/s00438-005-1148-3

Shaked, H., Kashkush, K., Ozkan, H., Feldman, M., and Levy, A. A. (2001). Sequence elimination and cytosine methylation are rapid and reproducible responses of the genome to wide hybridization and allopolyploidy in wheat. Plant Cell 13, 1749-1759. doi: 10.1105/tpc.13.8.1749

Shendure, J., and Ji, H. (2008). Next-generation DNA sequencing. Nat. Biotechnol. 26, 1135-1145. doi: 10.1038/nbt1486

Stroud, H., Ding, B., Simon, S. A., Feng, S., Bellizzi, M., Pellegrini, M., et al. (2013). Plants regenerated from tissue culture contain stable epigenome changes in rice. eLife 2:e00354. doi: 10.7554/eLife.00354

Sulistyaningsih, E., Aoyagi, Y., and Tashiro, Y. (2006). Flower bud culture of shallot (Allium cepa L. Aggregatum group) with cytogenetic analysis of resulting gynogenic plants and somaclones. Plant Cell Tiss. Org. Cult. 86, 249-255. doi: 10.1007/s11240-006-9114-2

Sun, C. Q., Chen, F. D., Teng, N. J., Liu, Z. L., Fang, W. M., and Hou, X. L. (2010). Factors affecting seed set in the crosses between Dendranthema grandiflorum (Ramat.) Kitamura and its wild species. Euphytica 171, 181-192. doi: 10.1007/s10681-009-0005-6

Tang, F., Chen, F., Chen, S., Teng, N., and Fang, W. (2009). Intergeneric hybridization and relationship of genera within the tribe Anthemideae Cass. (I. Dendranthema crassum (kitam.) kitam. $\times$ Crossostephium chinense (L.) Makino). Euphytica 169, 133-140. doi: 10.1007/s10681-009-9956-x

Teixeira da Silva, J. A., Shinoyama, H., Aida, R., Matsushita, Y., Raj, S. K., and Chen, F. (2013). Chrysanthemum biotechnology: Quo vadis? Critc. Rev. Plant Sci. 32, 21-52. doi: 10.1080/07352689.2012.696461

Thomas, W., Forster, B., and Gertsson, B. (2003). "Doubled haploids in breeding," in Doubled Haploid Production in Crop Plants, ed A. Manual (Dordrecht: Kluwer Academic Publishers), 337-349.

Vos, P., Hogers, R., Bleeker, M., Reijans, M., van de Lee, T., Hornes, M., et al. (1995). AFLP: a new technique for DNA fingerprinting. Nucleic Acids Res. 23, 4407-4414. doi: 10.1093/nar/23.21.4407

Wang, H., Jiang, J., Chen, S., Fang, W., Guan, Z., Liao, Y., et al. (2013b). Rapid genomic and transcriptomic alterations induced by wide hybridization: Chrysanthemum nankingense $\mathrm{x}$ Tanacetum vulgare and C. crassum $x$ Crossostephium chinense (Asteraceae). BMC Genomics 14:902. doi: 10.1186/1471-2164-14-902

Wang, H., Jiang, J., Chen, S., Qi, X., Peng, H., Li, P., et al. (2013a). Next-generation sequencing of the Chrysanthemum nankingense (Asteraceae) transcriptome permits large-scale unigene assembly and SSR marker discovery. PLoS ONE 8:e62293. doi: 10.1371/journal.pone.0062293

Wang, H., Jiang, J., Chen, S., Qi, X., Fang, W., Guan, Z., et al. (2014a). Rapid genetic and epigenetic alterations under intergeneric genomic shock in newly synthesized Chrysanthemum morifolium $\times$ Leucanthemum paludosum hybrids (Asteraceae). Genom. Biol. Evol. 6, 247-259. doi: 10.1093/gbe/ evu008 
Wang, H., Qi, X., Gao, R., Wang, J., Dong, B., Jiang, J., et al. (2014b). Microsatellite polymorphism among Chrysanthemum sp. polyploids: the influence of whole genome duplication. Sci. Rep. 4:6730. doi: 10.1038/srep 06730

Wang, J., Tian, L., Lee, H. S., Wei, N. E., Jiang, H., Watson, B., et al. (2006). Genomewide nonadditive gene regulation in Arabidopsis allotetraploids. Genetics 172, 507-517. doi: 10.1534/genetics.105.047894

Watanabe, K. (1977). Successful ovary culture and production of F1 hybrids and androgenic haploids in Japanese Chrysanthemum species. J. Hered. 68, $317-320$.

Wẹdzony, M., Forster, B., żur, I., Golemiec, E., Szechyńska-Hebda, M., Dubas, E., et al. (2009). "Progress in doubled haploid technology in higher plants," in Advances in Haploid Production in Higher Plants, eds A. Touraev, B. P. Forster, and S. Mohan Jain (New York, NY: Springer), 1-33. doi: 10.1007/978-1-40208854-4_1

Yang, J., Endo, M., and Inada, I. (2005). Anther and microspore culture of chrysanthemum (Dendranthema grandiflorum (Ramat.) Kitam.). J. Japn. Soc. Hortic. Sci. 74, 78-86. doi: 10.2503/jjshs.74.78
Conflict of Interest Statement: The authors declare that the research was conducted in the absence of any commercial or financial relationships that could be construed as a potential conflict of interest.

Received: 25 September 2014; accepted: 04 December 2014; published online: 22 December 2014.

Citation: Wang H, Dong B, Jiang J, Fang W, Guan Z, Liao Y, Chen S and Chen F (2014) Characterization of in vitro haploid and doubled haploid Chrysanthemum morifolium plants via unfertilized ovule culture for phenotypical traits and DNA methylation pattern. Front. Plant Sci. 5:738. doi: 10.3389/fpls.2014.00738

This article was submitted to Crop Science and Horticulture, a section of the journal Frontiers in Plant Science.

Copyright () 2014 Wang, Dong, Jiang, Fang, Guan, Liao, Chen and Chen. This is an open-access article distributed under the terms of the Creative Commons Attribution License (CC BY). The use, distribution or reproduction in other forums is permitted, provided the original author(s) or licensor are credited and that the original publication in this journal is cited, in accordance with accepted academic practice. No use, distribution or reproduction is permitted which does not comply with these terms. 